University of California, Hastings College of the Law UC Hastings Scholarship Repository

Faculty Scholarship

2017

\title{
Resolving Disputes and Improving Security in Post-Conflict Settings: An Example from Liberia
}

Jessica Vapnek

UC Hastings College of the Law, vapnekjessica@uchastings.edu

Alfred Fofie

Peter Boaz

Follow this and additional works at: https://repository.uchastings.edu/faculty_scholarship

\section{Recommended Citation}

Jessica Vapnek, Alfred Fofie, and Peter Boaz, Resolving Disputes and Improving Security in Post-Conflict Settings: An Example from Liberia, 83 Arbitration 288 (2017).

Available at: https://repository.uchastings.edu/faculty_scholarship/1634

This Article is brought to you for free and open access by UC Hastings Scholarship Repository. It has been accepted for inclusion in Faculty Scholarship by an authorized administrator of UC Hastings Scholarship Repository. 


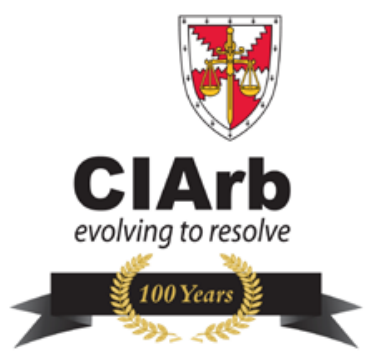

\title{
Resolving Disputes and Improving Security in Post-Conflict Settings: An Example from Liberia
}

\author{
Jessica Vapnek \\ Alfred Fofie \\ Peter Boaz
}

Reprinted from

(2017) 83 (3) Arbitration 288-301

Sweet \& Maxwell

5 Canada Square, Canary Wharf,

London, E14 5AQ

(Law Publishers)

SWEET \& MAXWELL 


\title{
Resolving Disputes and Improving Security in Post-Conflict Settings: An Example from Liberia
}

\author{
Jessica Vapnek
}

\author{
Alfred Fofie
}

Peter Boaz*

\section{Introduction}

Countries emerging from civil conflict in the developing world face numerous challenges that hinder reconstruction and peace building. These hurdles, many of which existed before the war and may have contributed to the civil strife, include poverty, unequal distribution of political and economic power, land disputes and exploitation or exclusion of groups on social, cultural, tribal or religious bases. Liberia emerged from 14 years of conflict in 2003 urgently needing to address many of these concerns, in particular the burgeoning number of land disputes and the looming threat they posed to peace, security and national reconstruction. A joint effort by the Government of Liberia and the US Government led to the formulation of the Mitigating Land Disputes in Liberia Project (MLDL) ${ }^{1}$ funded by the US State Department. ${ }^{2}$ The project was launched in late 2011 with the goal of developing innovative solutions to reduce conflict, address security concerns and improve crime prevention in two rural counties ${ }^{3}$ (Nimba and Lofa) in northern and northwestern Liberia, respectively. Largely because of crucial participation by local communities and because the programme was designed with a keen awareness of customary norms and practices, the project has had measurable impacts and offers a model for effective dispute and conflict resolution in a rural post-war setting.

This article first examines the role of land underpinning disputes in post-conflict settings and then outlines the origins of the MLDL project. Next, the article provides a snapshot of the system and examines the methodology and factors that led to the success of the dispute resolution and conflict early warning/early response system established and supported by MLDL. After reviewing selected disputes resolved and security issues addressed during the life of the project, the article concludes by suggesting the features of MLDL's dispute resolution and early warning model that could be replicated in other post-conflict regions.

\section{The role of land in conflict and peace}

Land is a valuable resource that can simultaneously have economic, social, cultural and political significance. ${ }^{4}$ It holds symbolic and practical importance as an economic resource

\footnotetext{
* The opinions expressed here are the authors' alone and do not imply the approval of the US Government or Tetra Tech DPK. The authors would like to thank Amy Bruins, Geralyn Busnardo, Jeffrey Collins, Amanda Dahan, Marinetta Cannito Hjort, Johnathan McCaskill, Robert W. Page, Jr., Rachel Sampson, Marti Troy and Helga Turku for comments and suggestions on this article. Thanks are also due to technical staff at the US State Department, in particular Andrea Lauritzen and Huber Parsons, who conceived the project and shepherded it through its early days.

${ }^{1}$ After one year of operation, the US State Department requested that the project's name change to Mitigating Local Disputes in Liberia (still MLDL), to reflect the fact that although land disputes are a critical risk to stability, other types of disputes also raise security concerns and contribute to destabilisation.

${ }^{2}$ Specifically, the Bureau of International Narcotics and Law Enforcement Affairs, known as INL.

${ }^{3}$ Liberia's 15 regions are known as counties, each led by a superintendent (governor).

${ }^{4}$ Sara Pantuliano and Samir Elhawary, "Uncharted Territory: Land, Conflict, and Humanitarian Action", Humanitarian Policy Group Policy Brief 39 (London: Overseas Development Institute, November 2009), pp.1 and 3.
} 
central to livelihoods; it is also a source of social legitimacy, a reflection of power in society, a basis of cultural identity and a symbol of belonging to a community. ${ }^{5}$ Land disputes are prevalent in post-war settings because the end of conflict usually leads to the return of displaced populations on a large scale. After years or decades living abroad, individuals return to their ancestral homes or legitimately purchased parcels of land to find that individuals or groups have claimed and occupied the land, at times for years. The resulting disputes threaten the fragile peace and stability of the recovering state if left unaddressed. ${ }^{6}$

Thirteen years after the end of the war, land disputes remain a volatile issue and a threat to peace in Liberia. ${ }^{7}$ The Liberia Truth and Reconciliation Commission, established in 2005 to investigate civil conflict in the country and to report on past human rights violations, warned of a "strong likelihood of Liberia's return to violence if the land issue was not adequately addressed". In $2008,62 \%$ of Liberians surveyed stated that land was the most important cause of violence and conflict in the country. ${ }^{9}$ Ethnic or tribal conflict, often closely associated with land disputes in this context, was the next most-cited risk (19\%). ${ }^{10}$ Nearly six in 10 respondents (59\%) stated that violent conflict over land ownership and distribution arises "often" or "always" in Liberia.

Land disputes in Liberia originate from many sources. They are particularly common in areas where opposing tribes fought heavily against one another during the civil war. Nimba County is home to the mutually distrusting Gio and Mano people, as well as to the Mandingo people who have historically feuded with both. In Lofa County, the Lorma (or Loma) and Kisi people have traditionally fought with the Mandingos. Tribal or religious groups can also create conflict by destroying the traditional land symbols of others; the desecration of Lorma sacred groves (a site for traditional ceremonies) by the Mandingo-Muslims in Lofa County is one such example. ${ }^{12}$ Nimba and Lofa also boast substantial natural resources - including minerals, lumber and wildlife - which can be another cause of conflict. Because of the movement of people and goods, border regions can be particularly volatile: Nimba and Lofa Counties share porous borders with Guinea and Sierra Leone, two nations that have also fought bitter civil wars.

Liberia's civil war forced many residents to seek refuge in other countries, and after the end of the conflict there was a high demand, and consequent rush, for land. In many cases vacant lands had been taken over by squatters unwilling to relinquish their claims. These illegal occupants usually demanded that the returning claimants provide valid documentation to support their claims of ownership - documentation that no longer existed (if it ever had), due to the conflict. Disputes over ownership were exacerbated by the breakdown of the formal legal system, which was not robust even before the conflict. As a result, struggles for land and other resources after the war's end generated tensions and violent conflicts

\footnotetext{
${ }^{5}$ John W. Bruce and Sally Holt, "Quick Guide to Land and Conflict Prevention, Initiative on Quiet Diplomacy, Handbook on Land and Conflict Prevention" No.6 (2003), p.11.

${ }^{6}$ Pantuliano and Elhawary, "Uncharted Territory: Land, Conflict, and Humanitarian Action" (2009) 39 Humanitarian Policy Group Policy Brief 1, 1, 3.

${ }^{7}$ Liberia International Conflict Vulnerability Assessment-Final Report, May 2016, p.13, http:/ /democracyinternational.com/media/Liberia\%20Conflict\%20Assessment\%20Final\%20Report\%20(External).pdf [Accessed 4 June 2017].

${ }^{8}$ The Afrobarometer, "Land Disputes in Liberia: Views From Below, 2008", Briefing Paper No. 72 (October 2009), p.1. The Afrobarometer is a series of public attitude surveys on democracy, governance, markets and economic conditions in Africa. It is produced collaboratively by social scientists from 20 African countries, with coordination provided by the Institute for Empirical Research in Political Economy in Benin, the Center for Democratic Development in Ghana and the Institute for Democracy in South Africa.

${ }^{9}$ The Afrobarometer, "Land Disputes in Liberia: Views From Below, 2008", Briefing Paper No. 72 (October 2009), p. 1 .

${ }^{10}$ The Afrobarometer, "Land Disputes in Liberia: Views From Below, 2008”, Briefing Paper No. 72 (October 2009), p.1.

${ }^{11}$ The Afrobarometer, "Land Disputes in Liberia: Views From Below, 2008”, Briefing Paper No. 72 (October 2009), p.1.

${ }^{12}$ cf. Sarah Brownell, "Rival ethnic groups smoke peace pipe in Liberia's Lofa county", 20 July 2005, www.unher .org/en-us/news/latest/2005/7/42de6c764/rival-ethnic-groups [Accessed 13 June 2017].
} 
throughout the country, often with an ethnic dimension. This resulted in the destruction of lives and property and forced some residents to flee once again.

Another source of conflict arose from the Government's turning over significant tracts of land to large companies, usually foreign, for mining operations. Under- or unregulated mining and logging, combined with rural population growth, puts intense pressure on land and water as local communities struggle to meet their needs for food and income. Seventy-one per cent of Liberians live in rural areas where over $85 \%$ of the population rely on forest land for livelihoods and survival. ${ }^{13}$ For all of these reasons, finding a lasting solution to persistent conflicts around land and other resources was a high priority of the Government of Liberia after the war and was the genesis of the MLDL project.

\section{Origins of the mitigating local disputes in Liberia project}

Liberia was relatively stable and peaceful in 2005 following democratic elections in 2004. Nonetheless, the country still faced a number of socio-economic, political and security challenges, including constant threats by former militia leaders to return to war, an alarmingly high rate of poverty and a large number of land disputes and associated ethnic and tribal conflicts. In its pursuit of solutions, the Government of Liberia began soliciting views through bilateral and multilateral engagements and nationwide consultations on how to strengthen national policies, in particular on security, to reduce the risk of a recurrence of conflict. These national reconstruction efforts, supported by the international donor community, resulted in the formulation of the Government of Liberia's Poverty Reduction Strategy launched in April 2008 and aimed at reducing poverty to meet the United Nations Millennium Development Goals. The strategy consists of four key pillars: (1) consolidating peace and security; (2) revitalising the economy; (3) improving governance and the rule of law; and (4) providing infrastructure and basic services.

In early 2009, Liberian Government representatives and national and international security experts met in the capital, Monrovia, to design a national security mechanism that would identify, prevent, resolve and report on security issues. The resulting system, consisting initially of County Security Councils (CSCs) at county level and District Security Councils (DSCs) at district level, ${ }^{14}$ was confirmed at a follow-up meeting in the Ministry of Internal Affairs (MIA) in Monrovia. Expected to serve as an early warning/early response mechanism on security issues, the CSC/DSC system was launched on 4 December 2009 in Kakata, Margibi County, at a ceremony attended by superintendents of Liberia's 15 counties along with the county commanders of the Liberia National Police, the Bureau of Immigration and Naturalization, the Liberia National Fire Service and the Corrections Service.

To support the CSC/DSC system - a new model of civilian-security collaboration - the Government of Liberia sought and received support from international partners. The US Government stepped up early, due to the US' important role in the history of Liberia and fears of renewed destabilisation if land disputes persisted unresolved. Thus in 2011, the Government of Liberia and the US Government agreed to implement a pilot programme with the goal of advancing peace and stability in two counties (Nimba and Lofa) that were particularly prone to land disputes. The pilot programme would establish a network of councils linking local communities with national policymakers. In November 2011, after a competitive procurement process, the US State Department awarded the MLDL project to Tetra Tech DPK, an implementer with experience in rule of law, alternative dispute resolution (ADR) and formal and informal justice systems in Africa and elsewhere.

Operating initially in the two pilot counties of Nimba and Lofa and now in two more counties (Bong and Grand Gedeh), all with histories of conflict, MLDL aims to improve

\footnotetext{
${ }^{13}$ The main activities include production of rice, cocoa, coffee, palm oil, sugar cane, cassava, cash crops, livestock, fishery, forestry (mainly pit sawing and charcoal production) and illicit mining.

${ }^{14}$ The CSCs are headed by County Superintendents while the DSCs are headed by District Commissioners.
} 
the relationship between citizens and local institutions and to collect vital information on community concerns and security issues. In the belief that the DSCs did not reach far enough into the grassroots level, the project proposed to create Community Forums (CFs) as the lowest level community venue to identify and address local security concerns and report unresolved disputes up the chain to DSCs, CSCs, and, in exceptional circumstances, the National Security Council (NSC). As the third leg of the stool, the CFs complete the conceptual framework initially proposed by the Government of Liberia, providing an opportunity for public participation in national security governance and citizen involvement in identifying and resolving disputes at the local level. Engaging local populations in governance also reduces the risk of violent extremism, which can take root in remote areas with weak government oversight. ${ }^{15}$

Since the project launch in 2011, MLDL has provided extensive training and mentoring to the CFs, DSCs and CSCs. During its first phase, ${ }^{16}$ MLDL also helped strengthen the capacities of law enforcement by providing limited material support to police, training police officers on community policing and investigations, and working with existing volunteer groups dedicated to monitoring crime in their communities. ${ }^{17}$ The objective was to improve the ability of security actors to respond to disputes and crimes, thereby reducing conflict (as many larger conflicts start as minor crimes or disputes). The policing activities were intended to complement the work of the $\mathrm{CF} / \mathrm{DSC} / \mathrm{CSC}$ network, helping to head off any brewing conflicts and to improve public perceptions of the police and other government officials, all in the service of advancing stability and peace.

\section{Snapshot of the system and its structures}

The system implemented by MLDL has been designed such that the CFs identify local disputes and security issues at the grassroots level and provide solutions where possible. They refer situations beyond their dispute resolution capacity up the chain to DSCs, which do the same vis-à-vis the CSCs. ${ }^{18}$ The system gives communities a role in resolving disputes at the local level while also ensuring that the regional and national authorities have the most up-to-date information on security concerns facing residents of rural areas. This two-way information flow fosters local participation, improves government response and increases trust between citizens and their local and national government representatives.

One of the system's most successful interventions was to resolve a dispute that had been brewing for nearly four decades between two communities in the Buu-Yao district of Nimba County, near the Côte d'Ivoire border and close to the scene of the first hostilities in Liberia's civil war. In 1976, the Yeaten family encroached upon the farmland of the Nutuah family, but in 1983 a local traditional court ruled in favour of the Nutuah family and the Yeaten family relinquished the disputed land. Grumblings of discontent, however, surfaced during Liberia's civil war. In the 1990s, the Yeaten family forcibly took back the disputed land and even encroached further, under the protective orders of their son, Benjamin Yeaten, then a Major-General in rebel leader Charles Taylor's National Patriotic Front of Liberia. Even when Benjamin Yeaten became a fugitive, the Yeaten family continued to farm the ill-gotten land while the Nutuah family retaliated by encroaching on a parcel of the Yeaten land. The local traditional elders attempted to resolve this intractable land dispute many

\footnotetext{
${ }^{15}$ United States Agency for International Development (USAID), "The Development Response to Violent Extremism and Insurgency", p.3, https://www.usaid.gov/sites/default/files/documents/1870/VEI_Policy_Final.pdf[Accessed 13 June 2017].

${ }^{16}$ MLDL Phase I was implemented by Tetra Tech DPK and ran from November 2011 to December 2014, while MLDL Phase II (which began in December 2014 and will run until December 2017) is currently being implemented by The Kaizen Company in partnership with Tetra Tech DPK.

${ }^{17}$ MLDL Phase I trained and supported Community Watch Forums, non-profit volunteer groups of concerned citizens serving as the "eyes and ears" of the under-resourced and under-staffed police and working to identify potential flashpoints before they escalate into crime or conflict. MLDL provided modest resources including flashlights, mobile phone credit, and rain ponchos to the Community Watch Forums to facilitate their work.

${ }^{18}$ The membership and role of each of these will be outlined in more detail in the next section.
} 
times to no avail. When the Buu-Yao DSC and Gbloulay CF, structures created with MLDL assistance, stepped in to resolve the dispute with modest logistical support and mentoring by the MLDL team, local leaders were highly sceptical and expressed their doubts that reconciliation would be possible.

The mediation team, comprised of 15 Gbloulay CF members and three Buu-Yao DSC members, successfully applied a mix of traditional and modern ADR processes over four days. Despite the difficulty in reaching the area of conflict for the consultations (whether by motorcycle or on foot), the mediation went smoothly. The Yeaten family addressed the assembled group and aired their grievances dating back to the 1983 settlement. They then listened to the opposing views of the Nutuah representatives, and in the end agreed to let go of the disputed land. Both families signed memoranda of understanding in a subsequent ceremony, at which time the father of fugitive Benjamin Yeaten knelt before the Nutuah family and asked for forgiveness, signalling the end of the enmity that had persisted between their communities. The Nutuah community responded positively, agreeing to return the land they had taken and emphasising that all past animosity was over. MLDL staff and the mediation team successfully guided those involved in the land disputes to a harmonious resolution, and at the time of writing, the peace accord between the two families is still holding.

In addition to resolving disputes like these, the network of forums and councils serves as an early warning/early response mechanism, because the CF, DSC and CSC meetings identify potential flashpoints and facilitate timely government reactions. In early 2016, the early warning/early response system proved highly effective when three different DSCs in Nimba County independently raised concerns regarding the proliferation of pistols and other single-barrelled guns, particularly among young people. They referred the issue to the Nimba CSC, which immediately recognised the scope of the security threat and elevated the issue to the NSC through the MIA. The NSC, in turn, passed the report directly to the desk of the President of Liberia, Ellen Johnson Sirleaf.

The report provided by the Nimba CSC helped President Sirleaf better understand the threats posed by guns in rural communities and prompted her to instruct the Liberia National Commission on Small Arms to take action. In response, the Commission developed a three-pronged programme that educates citizens on the dangers of firearms, provides compensation to informants and manages newly established voluntary firearm collection points in four counties, including Nimba.

Information coming from the forum and council meetings spurs prompt and appropriate government response and allocation of resources to address security issues in remote areas while also providing up-to-date information to higher-level officials as they formulate national security policy. Improving government response is particularly important in developing countries like Liberia where the lack of adequate roads and communication networks makes it difficult for central governments to establish their authority in isolated and rural regions. Governments find it especially challenging to maintain a security presence in such regions where formal institutions may be weak or non-existent, the populace often distrusts the government and the risks of violent extremism are high. As noted in a US Government policy report:

"Poorly governed or ungoverned areas may enable violent extremists to establish sanctuaries or safe havens. Poorly governed areas may create passive or active support for such groups by communities who feel marginalized or neglected by a lack of government reach." 19

For this reason, involving remote communities and giving young people, in particular, a role in community governance is "an important option for turning a potential source of

\footnotetext{
${ }^{19}$ USAID, “The Development Response to Violent Extremism and Insurgency”, p.3.
} 
instability into an asset". ${ }^{20}$ The CFs, DSCs and CSCs, which bring local residents and government officials together, are serving this larger purpose.

The next sub-sections introduce in more detail each of the structures making up the security and early warning/early response system.

\section{Community forums}

The CFs comprise leaders at the most local level, including town chiefs and civil society representatives. Because of their local character, the CFs provide the ideal space for identifying community security concerns and facilitating their resolution via informal means of mediation and conciliation. Historically, elders in rural areas used mediation to help resolve conflicts in the community, and the CFs established with MLDL support strengthen and build on this cultural tradition, incorporating its benefits into the national security apparatus.

If a small dispute arises in a town or village, the members of the CF are obliged to identify the parties involved and move the dispute into mediation. If they cannot resolve the dispute, the issue is passed on to the DSC. In the past, when local disputes were not resolved, disputing parties would have had no further recourse because the interior areas of Liberia receive scarce resources from the national Government. In particular, the court system barely covers the remote areas, and even where it exists it is inefficient, at times requiring disputants to wait years for a case to conclude. Corruption is also an issue, and so for all of these reasons, many disputes linger unresolved and create tension, instability and animosity in local communities. The newly established CFs now functioning in several of Liberia's counties target and make every effort to resolve these local disputes, in the hope of reducing conflict, building trust and fostering stability. Disputes not resolved at the CF level are passed up the chain to the DSC, then to the CSC and then to the NSC (through the MIA), if necessary.

\section{District security councils}

Liberia's National Security Strategy directs that the DSCs, like the CSCs, include both government and civil society representatives. ${ }^{21}$ Thus the DSCs have representation of both traditional leaders and formal state authorities, including paramount chiefs, district officials and law enforcement officials. The DSCs receive information from the grassroots (i.e. CF) level and identify the appropriate next steps to quell security concerns. Isolated incidents and minor disputes not resolved at the CF level are generally resolved at the DSC level, although persistent land disputes or volatile security concerns are passed along and up the chain to the relevant CSC.

\section{County security councils}

The CSCs are modelled on Liberia's NSC and are responsible for security policy co-ordination at the county level. The CSC mechanism is codified in Liberia's 2011 National Security Reform and Intelligence Act s. $5^{22}$; each CSC is chaired by the superintendent of the county, while other members include county heads of police, immigration and the fire service, and civilian authorities such as the paramount chief, clan chiefs and town chiefs. ${ }^{23}$ The CSC has significant authority to allocate resources to security crises anywhere in the county, and it maintains a direct line of communication to the national Government in

\footnotetext{
${ }^{20}$ USAID, "The Development Response to Violent Extremism and Insurgency", p.5.

${ }^{21}$ National Security Strategy of the Republic of Liberia (2008), p.4, issat.dcaf.ch/fre/content/download/16050 /188151/file/NSSRL.docx [Accessed 13 June 2017].

${ }^{22}$ National Security Reform and Intelligence Act 2011 s.5, Ministry of Foreign Affairs, Liberia.

${ }^{23}$ Ibrahim Al-bakri Nyei, Toward Security Sector Decentralization: Liberia's County Security Councils and Regional Hubs" (Monrovia: Centre for Security Governance, 2015), p.3.
} 
Monrovia and can immediately inform the central authorities of any dangerous situations that may require support.

The CSCs report to the Minister of Internal Affairs (a member of the NSC) through the Coordination Secretariat located in the MIA in Monrovia. The Secretariat acts as the linchpin, consolidating information from the CSCs and co-ordinating with other government agencies as needed. MLDL helped establish and provision the Coordination Secretariat, which receives regular monthly reports from CSCs and works to ensure communication among the CSCs, the MIA and the NSC.

One commentator describes the CSCs thus:

"The local councils are part of the national peace-building efforts to ensure security and peace coordination at the levels of the counties and the districts. The CSC is coordinated through a multifaceted platform with government, civil society, and other local stakeholders acting together, and they are not only responsible for physical security but also act as a mechanism for disaster and crisis management. Through the $\mathrm{CSC}$, civilian players can participate in decision making processes in the security sector. This facilitates a process in which national security policies are informed by both physical security issues and more human-related ones, from socio-economic to disaster management." ${ }^{24}$

Since December 2009, 12 CSCs have been established, four of which are currently receiving support from MLDL: those in Bong, Grand Gedeh, Lofa and Nimba counties. The remaining eight CSCs are self-supporting, and six of these were only reactivated in 2016. As they have not received any external support, these new CSCs generally meet sporadically and do not send reports to the NSC, which limits their present functionality. ${ }^{25}$ Based on the success achieved with the first four CSCs, there is little doubt that these other CSCs would also attain the same operational level were they to receive similar support in the form of capacity building, sustainability planning and resources.

\section{Methodology and key success factors}

MLDL Phase I's principal task was to establish pilot CFs, DSCs and CSCs in the two counties, Nimba and Lofa, and build their capacity to identify security concerns, resolve disputes, and self-govern. MLDL Phase II expanded the mechanism to two more counties, Bong and Grand Gedeh. This section examines the methodologies and strategies used and identifies the factors that led to the successful implementation of the dispute resolution and early warning/early response mechanism in these four counties.

\section{Local ownership and leadership}

The most important strategy and success factor for MLDL was its commitment to local ownership and local leadership from the outset. Local ownership in this context means that because "a justice and security sector reform process is of integral concern to the local population", local representatives should be integrally involved in its formulation. ${ }^{26}$ Local

\footnotetext{
${ }^{24}$ Ibrahim Al-bakri Nyei, Toward Security Sector Decentralization: Liberia's County Security Councils and Regional Hubs" (Monrovia: Centre for Security Governance, 2015).

${ }^{25}$ As of 2016, it is only in Bong, Grand Gedeh, Lofa and Nimba counties that the CSC/DSC/CF mechanism is functioning as originally envisioned by the Government of Liberia, and this is due to key donor support from the US Government. The self-supported CSC/DSC/CF mechanism has existed in Montserrado and River Gee counties since 2010 and was revived in 2016 in Bomi, Gbarpolu, Grand Bassa, Grand Cape Mount, Margibi, and Maryland counties. Three counties - Grand Kru, Rivercess, and Sinoe - lack the system entirely. With MLDL always having been described as a pilot programme, and with its efforts having been discussed widely on radio and in the news, there is a lot of community interest in the programme. Government officials and the public at large are hoping for support, whether from the US Government or another donor, to expand the system to Liberia's remaining counties.

${ }^{26}$ Annika Hansen and Sharon Wiharta, "The Transition to a Just Order-Establishing Local Ownership After Conflict, A Policy Report”, Folke Bernadotte Academy (2007), p.xvii.
} 
ownership is increasingly accepted as a precondition for effective development assistance, ${ }^{27}$ as contrasted with a "vision of development in which all the answers and all the agency are seen to lie in the hands of foreigners". ${ }^{28}$ The consensus is that programmes not shaped by the local culture and driven by local actors are unlikely to be implemented properly or sustained. ${ }^{29}$

To this end, MLDL engaged local experts to ensure that the dispute resolution system to be used would embody the local culture. Thus the system emphasises traditional community-based concepts of justice rather than more punitive and retributive measures. In a tight-knit rural community based on family, clan and tribe and anchored in social relationships, to simply punish someone who commits a crime and then expect him or her to easily reintegrate back into the society is not realistic and usually contributes to more social instability. It is for this reason that the:

"African indigenous justice system employs restorative and transformative principles in conflict resolution[, whereby v]ictims, offenders and the entire community are involved and participate in the definition of harm and search for resolution acceptable to all stakeholders". ${ }^{30}$

A dispute resolution framework that allows all parties to air their grievances and that involves all of them in designing and agreeing on a solution - as in the example introduced in s.4 above - is therefore much better positioned to attract lasting support and explains MLDL's success in generating enduring solutions to conflict, fostering reconciliation and preventing crime.

In addition to ensuring that the dispute resolution techniques were culturally appropriate, MLDL developed and now replicates a series of actions to foster local leadership, so that interventions are not viewed as imposed from outside but rather have their genesis in the community. This endeavour can be delicate in the context of a donor-funded initiative, which by its nature provides funding from outside, but MLDL's success was due both to the astute and nuanced leadership of the project and to the fact that the idea for the security mechanism came from the Government of Liberia itself.

To foster local leadership, at the start of each effort to establish a new CF or DSC, MLDL staff first conduct an assessment of a community to gather information on prospective forum or council members and to lay the groundwork for the establishment of the new security structure. The team then approaches the leaders of the relevant village, town or city and introduces the MLDL project and its work, and the leaders, chiefs and government officials then confer with other town members to decide which residents should be nominated to serve. Vetting of each proposed candidate follows, including interviews, references and recommendations from colleagues and peers. Thereafter, MLDL staff and local leaders discuss and carefully examine and finalise the list. The local officials and MLDL jointly plan the inaugural ceremonies and project-led training sessions (on the role of the forum/council and on the early warning/early response concept) for the members of the new structure.

The successful implementation of a programme such as MLDL in a rural area with a high illiteracy rate requires caution, tact and persuasion to win over prospective partners. This is achieved by the project engaging in a deliberate and elaborate process of identifying

\footnotetext{
${ }^{27}$ Timothy Donais, “Understanding Local Ownership in Security Sector Reform”, in Local Ownership and Security Sector Reform, the Geneva Centre for the Democratic Control of Armed Forces Yearbook, 6th edn (Geneva: Geneva Centre for the Democratic Control of Armed Forces, 2008), p.3.

${ }^{28}$ Joseph Stiglitz, "Towards a New Paradigm for Development: Strategies, Policies, and Processes", Prebisch Lecture (New York: UNCTAD, 1998).

${ }^{29}$ Timothy Donais, "National Ownership and Post-Conflict Peace Building: From Principle to Practice", Policy Brief No.43 (Waterloo: Centre for International Governance Innovation, 2014), p.1.

${ }^{30} \mathrm{O}$. OkoElechi, "Human Rights and the African Indigenous Justice System", Center for Justice and Reconciliation, http://restorativejustice.org/rj-library/human-rights-and-the-african-indigenous-justice-system/5449/[Accessed 13 June 2017].
} 
and courting the most influential local leaders such as chiefs, local government administrators, civil society representatives and others in each community and assuring them that their participation is essential. This also fosters a sense of buy-in among community members. This was particularly crucial in 2012, when MLDL began, because the perception was rife that Liberia and its rural areas had been "assessed to death" by an assortment of experts and consultants without much to show in the way of tangible improvements in people's lives. The MLDL team took these considerations into account, using widespread consultations to constantly reiterate the message that security is everyone's concern and that MLDL's role is just to facilitate. Cultivating and relying on local leadership - with MLDL staff taking a back-seat role in public gatherings - has been key to generating and maintaining support for the initiatives.

\section{Community policing}

In addition to establishing the three levels of structures (CFs, DSCs and CSCs), MLDL Phase I worked with local civilian police to build their investigative skills and strengthen their ties with communities. ${ }^{31}$ The project's training programmes covered crime investigation techniques, witness interviewing skills, preservation of evidence and crime scene management, mediation, the role of law enforcement officers in society, criminal intelligence, organised crime and community policing. MLDL provided material resources, such as crime investigation kits and motorbikes, to improve police response, while working to increase community support for law enforcement. As noted, ${ }^{32}$ MLDL worked with community crime watch groups to complement official police activity.

Just as it did in working with the security structures (CFs, DSCs and CSCs), MLDL vigorously pursued a strategy of local ownership and local leadership for its work with the police. The project acted in a facilitative role, helping the police work with communities in devising and implementing solutions that were "tactfully and carefully tailored to the local conditions and cultures". ${ }^{33}$ This community-policing approach not only imbued local police with buy-in and a sense of ownership of the project's activities but also helped them build needed trust as they worked with and alongside community partners.

The importance of community-oriented policing cannot be over-emphasised. Through judicious design of community policing activities, MLDL worked to improve the relationship between citizens and their local security institutions so as to better identify and respond to crime and potential flashpoints of future conflict. Provision of minimal equipment, such as flashlights and rain ponchos, motivated members working in community watch groups to support the under-resourced police in identifying and reporting crime. And as noted earlier, involving the local population in governance can erode support for violent extremist groups in communities that otherwise feel "marginalized or neglected by a lack of government reach". 34

\section{Equipment and material support}

Too often, foreign-funded activities are viewed as temporary or evanescent, disappearing upon a project's end date. For this reason, the US State Department and MLDL have decided that helping the security structures build or acquire a venue for meetings and offices is important both symbolically and operationally, because it convinces local actors of the permanency of the initiative and fosters sustainability. Accordingly, MLDL has provided

\footnotetext{
${ }^{31}$ MLDL Phase II did not include work on policing.

${ }^{32}$ MLDL Phase I trained and supported Community Watch Forums and provided modest resources to facilitate their work.

${ }^{33}$ Global Counterterrorism Forum, "Good Practices on Community Engagement and Community-Oriented Policing As Tools to Counter Violent Extremism", p.1, https://www.thegctf.org/documents/10162/159885/13Aug09_EN_Good + Practices + on + Community + Engagement + and + Community-Oriented + Policing.pdf [Accessed 13 May 2017].

${ }^{34}$ USAID, "The Development Response to Violent Extremism and Insurgency", p.5.
} 
some funding for meeting venues. However, because the funding is limited, MLDL also encourages CFs and DSCs to find their own avenues to raise funds for temporary or permanent shelter, for example by appealing to local government authorities.

MLDL generally provides each CF, DSC or CSC with some equipment and material as well, with the goal of building popular support for and improving the effectiveness of these security mechanisms. Provisions have included generators, motorbikes, public address systems, office furniture, computers, printers and solar panels, particularly in the more remote rural areas. When the project was working with law enforcement, MLDL provided motorcycles to the local security agencies and crime scene investigation equipment to the police. With these new materials, police now have the ability to reach remote areas they could not access before. Such modest investments in equipment and supplies improve the effectiveness and raise the profile of the security structures, convincing local residents that they are not temporary, foreign or outside initiatives and building trust in their local government representatives.

\section{Capacity building}

Capacity building is another key feature of the MLDL approach. With an eye to sustainability, the project focuses on developing and strengthening the skills of the members of the CFs, DSCs and CSCs to perform their functions. ${ }^{35}$ Capacity building mainly takes the form of mentoring and training in mediation and dispute resolution methodologies, although the project has also covered more mundane topics such as how to run meetings, track security issues raised and prepare minutes and progress reports. After establishing one of the structures, MLDL staff conduct assessments of the members and leaders to determine their level of capacity and training needs. Thereafter, MLDL develops training plans and teaching materials and conducts training sessions to equip members of these structures with the knowledge and tools to undertake their responsibilities. Project funds are used to supply key expertise not available locally: for example, the project hired an international expert in ADR to prepare a comprehensive mediation manual tailored to the local context; another expert prepared survey tools; and still another developed a tool to report on and map community concerns and security incidents.

With the goal of enabling trainees to use their training almost immediately, the MLDL team steps aside so that the CFs, DSCs and CSCs organise and run their own meetings, with MLDL providing guidance only as requested. CFs, DSCs and CSCs prepare and distribute reports of their meetings and use the reporting tool to track security concerns and pending disputes. Local ownership, capacity building and sustainability are mutually reinforcing here: the structures are established with local leadership, are trained and equipped to lead meetings and activities from the outset and are therefore well placed to continue functioning after the end of the project.

\section{Examples of disputes and security issues addressed}

As seen in the example set out in s.4 above, the MLDL project has helped resolve even long-standing disputes that were exasperating local residents and officials. During its almost five years of existence to date, the project has continued successfully resolving disputes and has garnered the trust of local community and government leaders. A belief in the objectivity of the project, its staff and the newly established structures has led traditional authorities and government officials to bring security concerns or disputes - some of which had festered for years - to the attention of the MLDL team for resolution by the CF/DSC/CSC network. A snapshot of some of the issues addressed is set out here.

\footnotetext{
${ }^{35}$ In Phase I, MLDL also helped to build the capacities of the police and other law enforcement agencies.
} 


\section{Using early warning/early response systems}

One example of the effective use of the early warning/early response approach occurred during the Ebola outbreak in Liberia in 2014, which posed a serious security threat to the then two pilot counties and the entire country. Throughout this period, the MLDL-established structures were actively involved in implementing the government-recommended safety procedures and activities, particularly in addressing potential Ebola-related unrest at the local level. With support from the MLDL team, the CFs, DSCs and CSCs exercised their early warning/early response role, implementing appropriate local initiatives and actions and reporting emerging and problematic security concerns higher up the chain, all the way to the NSC and Ministry of Health in Monrovia. Local concerns were brought to the attention of central authorities which then modified national security and health policies and protocols taking into account local realities, while also giving support and material assistance to combat the epidemic. Equally, on a practical level, the MLDL-provided motorbikes allowed local representatives to reach remote areas to implement the health procedures and policies. During the most severe episodes of the epidemic, when MLDL could not operate in the most affected areas, some of the security structures served as important community-based co-ordination centres for the distribution of Ebola-related support provided by the Government and the international community. They also continued to serve as key information resources for the central government as it tried to contain and ultimately eradicate the disease. In serving these vital functions for remote and previously unreachable populations, and without external support or direction, the structures demonstrated their effectiveness and sustainability.

Another example of the early warning/early response system was when the CF in the town of Gbloulay dispersed an angry group of citizens in 2013 planning a violent attack in the town of Tiahplay. The Chair of the Gbloulay CF was notified by a community member that a murder had taken place and that the victim's family was gathering youths in preparation for a revenge attack. Recognising the extreme urgency of the situation, the Chair called CF members and volunteers and asked them to immediately station themselves at the intersection of the road leading to Tiahplay, to intercept the crowd and dissuade them from violent retaliation. The Chair and the intervention team directly addressed the angry mob, asking them to trust the CF and its partner MLDL, which had already informed the Liberia National Police of the situation. The arrival of the police's Emergency Response Unit calmed the situation, the crowd dispersed and the murder suspects were subsequently arrested. The fact that the rule of law prevailed confirms the important role of the early warning/early response system in breaking cycles of retribution, decreasing conflict and improving public confidence in state security and justice structures. The same community faced another potentially violent situation in 2015 . They sought MLDL assistance to reach a peaceful resolution, again highlighting the importance of a permanent, community-led structure to handle disputes and security concerns in remote conflict-prone areas and to pacify youths who may otherwise be susceptible to calls for violence and retribution.

\section{Improving relations with a mining company}

When the MLDL team began operations in Nimba County in 2012, it encountered community members frustrated by an international corporation's mining practices that negatively affected land and water use. Residents were unaware of any means by which they could convey their complaints to the company. MLDL staff offered advice and shared negotiation techniques that the community could use, and at a subsequent town hall meeting, more than 100 community members affected by the mining practices expressed their grievances and requested safe drinking water, fair compensation for cash crops, funding for alternative livelihoods and resettlement to non-mining areas. The issues, along with the affected community's proposed solutions, were conveyed to the Nimba CSC, which agreed to 
intervene and subsequently established a committee to work with the corporation and the local representatives.

The Nimba CSC continued to provide a platform for citizens to express concerns over the mining activities during the years to follow. At one Nimba CSC meeting, the Liberia National Police and several members of the council reported an event that had endangered multiple towns. The mining company had conducted blasting exercises during the night without giving advance notice to the public. Not knowing the origin of the blasts, entire communities panicked, which resulted in looting, people going into hiding and rumours throughout the region that members of one ethnic group or another were attacking or planning attacks. The CSC agreed to convey an urgent communication to the company that in the future it should provide notice to the community on the radio prior to blasting, and the company agreed. This non-confrontational approach reinforced the importance of using the new channels of communication to address pending issues before they fester and grow.

Communities throughout the developing world face increasing attention from multinational corporations, some of which use illegitimate practices. Natural resource extraction, in particular, can negatively affect the economic, environmental and social well-being of local communities. The MLDL model can be replicated in any similar contexts to give a stronger voice to local stakeholders whose views may otherwise be overlooked.

\section{Resolving a school strike}

MLDL successfully helped resolve a strike action by the academic and support staff of the Child Friendly School in Ganta, Nimba County, in 2014. The school was built by UNICEF because there is a large population of school-age children but insufficient space in the government schools in Ganta, despite a guarantee of free primary education. The teachers had been engaging in intermittent strike actions on several occasions, their main grievance being eight months of unpaid salaries. Among the many security concerns stemming from the strike were the potential for violence and the long-term risks associated with young people not attending school. Matters worsened, with students and parents resorting to street demonstrations for several days in support of the teachers. Monitoring and controlling the student protests, on top of performing everyday police duties, also began to affect the already under-resourced and over-stretched Ganta police. The strikers rejected overtures by local government officials, and the dispute seemed intractable.

The Ganta CF, having been mentored to detect looming conflict, saw the need to respond to the strike action and quickly convened a meeting with a cross-section of community actors. Although recognising the position of the teachers and their frustration at working for such a long period without pay, the Ganta CF appealed to them to take into account the plight of the young people and their need for stability and an uninterrupted education. The teachers accepted the appeal of the Ganta CF to go back to their classes, and in return, the $\mathrm{CF}$ pledged to use its access to higher authorities in the county and in Monrovia to seek a lasting resolution to the dispute. The Nimba CSC took up the issue with the Ministries of Education and Finance in Monrovia, and eventually the back salaries were paid.

\section{Preventing mob violence}

An incident in the Buu-Yao District in 2015 involved a man who was attacked by two other men from a different village. He killed one of the men in self-defence and fled to his village police station. The on-duty policeman took him into protective custody but subsequently fled when a large group of men from the deceased's village came looking for revenge. The mob murdered the man at the police station, which led to demands for retaliation from the victim's family. MLDL staff, in close co-operation with the village leadership from both sides, convinced the communities to let the formal justice system run its course. Unfortunately, some suspects alleged to have been involved in the murder at the police 
station were released prematurely. Tensions between communities rose once more, as the victim's community sought to recapture the accused persons from the opposing village.

In part due to telephones donated by MLDL, local DSC and CSC members were aware of developments in the area and were able to prepare a response before tensions erupted into violence. The Nimba County Superintendent, who was still relatively new to the position, initially intended to approach the matter from a strict law enforcement perspective, but he quickly saw that he could get a better response from the villages by speaking to them as a community leader. Accordingly, MLDL, at the behest of the Superintendent's Office, organised a community event that featured an anti-mob violence message and aimed to dispel some of the rumours that had been circulating. The town then hosted a mediation session led by a senior law enforcement official. Following this intervention, the community that was protecting the suspects agreed to transfer them to law enforcement officials, while the members of the other community agreed to respect the formal justice process and not take matters into their own hands.

\section{Conclusion}

Many countries share the same types of cultural, economic and political characteristics that have contributed to prolonged discord in Liberia. An emphasis on community participation, local ownership, local leadership and capacity building has earned the MLDL project a position of trust in resolving disputes in rural communities and conveying security concerns up and down the chain from local to regional to national and back again. There is every reason to believe that the methodology conceived by the Government of Liberia and developed by MLDL can be replicated elsewhere to help resolve disputes and prevent conflict and violence. For example, the early warning/early response system could address the precarious security situation in the western region of Côte d'Ivoire, where local land disputes are responsible for persistent instability and the insecurity of the local population. Issues loom larger in communities that are suspicious of central government involvement and look more to traditional or religious leaders for guidance. Many regions in Africa and elsewhere face these challenges and could benefit from MLDL's methodologies.

One appeal of the MLDL framework is its sustainability. The discussion above highlighted the importance of savvy involvement of local leadership in creating the structures, which generates local buy-in. The fact that the dispute resolution framework is drawn from the local culture also leads to its acceptability. Early success in resolving key disputes builds on initial investments and fosters long-term interest in perpetuating the early warning/early response system. With Liberian Government personnel and civilians serving together on the DSCs and CSCs, the councils benefit from both government support and popular interest, which makes their continuing existence more likely. In addition, their equipment, resource and infrastructure needs (meeting rooms, transportation and communication) are modest, which bodes well for sustainability. The other structures (CFs and Community Watch Forums) draw their membership mainly from community residents who are motivated to improve their local security, so again minimal resource support is required. Because these structures are not dependent on donor funds, their prospects for sustainability are high.

The Governments of Liberia and the US had a vision for how to identify and address long-standing disputes in Liberia. They were convinced that an effective governance structure for national peace and security requires the co-ordination and integration of actors at the national and local levels. The multi-layered system was implemented initially by experienced rule-of-law implementers, using a modest amount of funding in a short period of time (approximately $\$ 1.6$ million per year). The system saw success not only with land disputes; as interest grew, community members started identifying and the institutions started resolving other types of disputes and addressing other security concerns, some of which were described in this article. The project-created structures saw success because they originated in Liberian-owned plans and were designed to reflect the local culture. Thus, for example, 
they embody a restorative justice perspective which views community ties as a higher priority than punishment or retribution. The system is continuing to strengthen community ties, improve the ability of local organisations to identify potential flashpoints before they erupt into violence, reduce the risk of violent extremism and prevent crime. In this way, MLDL has been helping Liberia's peace-building efforts, an endeavour that could transform the continent were it implemented more widely. 